\title{
Prevalence of enteric bacteria and their antimicrobial susceptibility patterns among food handlers in Gondar town, Northwest Ethiopia
}

\author{
Michael Getie ${ }^{1}$, Wondwossen Abebe ${ }^{2^{*}}$ and Belay Tessema ${ }^{2}$
}

\begin{abstract}
Background: Enteric bacterial pathogens are the major causes of food-borne gastroenteritis in humans and remain important public health problems worldwide. The emergence of antimicrobial resistance is a global concern, particularly in developing countries. The aim of this study was to determine the prevalence of enteric bacteria pathogens and their antimicrobial susceptibility patterns among food handlers in Gondar town, Northwest Ethiopia.

Methods: A cross-sectional study was conducted from February 4 to April 16, 2018. A total of 257 food handlers were selected using a multistage sampling technique. Data on socio-demographic characteristics were collected using a structured questionnaire. Stool samples were collected and inoculated into appropriate media. Enteric bacterial pathogens were identified using standard microbiological methods. Antimicrobial susceptibility tests were performed using the disk diffusion technique as per the standard Kirby-Bauer method. Data were entered and analyzed using SPSS version 20 software.

Results: The overall prevalence of enteric bacteria was 34/257 (13. 2\%, [95\% Cl, 8.9-17.5\%]). Shigella species was the leading isolate that accounted for 26/257 (10.1\%) followed by Enterohemorrhagic Escherichia coli (EHEC) O157: H7 5/257 (1.9\%) and Salmonella species 3/257 (1.2\%). Shigella spp. was susceptible to ciprofloxacin 26 (100\%), ceftriaxone 25 (96.1\%), chloramphenicol 24 (92.3\%), nalidixic acid 24 (92.3\%), and gentamicin 20 (76.9\%). Escherichia coli O157: H7 and Salmonella spp. showed the maximum (100\%) susceptibility results to ceftriaxone, chloramphenicol, ciprofloxacin, and gentamicin. The overall prevalence of Multidrug resistance (MDR) in the current study was 14/34 (41.2\%).

Conclusion: Our study showed high prevalence of enteric bacterial pathogens among food handlers. All isolates were susceptible to ciprofloxacin. However, a substential number of isolates were resistant to commonly prescribed antibiotics and the prevalence of MDR was high.
\end{abstract}

Keywords: Food handlers, Enteric bacteria, Antibiotic susceptibility

\section{Background}

World health organization, food borne disease burden epidemiology reference group estimated that 31 food borne diseases (FBD) resulted in over 600 million illnesses and 420,000 deaths in 2010 globally. However, there were considerable differences in the burden of food borne diseases

\footnotetext{
* Correspondence: wondisweet@gmail.com

${ }^{2}$ Department of Medical Microbiology, School of Biomedical and Laboratory Sciences, College of Medicine and Health Sciences, University of Gondar, P.O.Box:196, Gondar, Ethiopia

Full list of author information is available at the end of the article
}

among sub regions delimited on the basis of child and adult mortality. The highest burden per population was observed in Africa [1]. It is estimated that more than 200 types of diseases transmitted to human through the ingestion of food contaminated with microorganisms or with chemicals. Food contamination can occur at any stage of food production, food processing, food storage and preparation in restaurant and hotels. Contamination can arise because of the pollution of the water, soil or air or through poor food-handling practices such as failing to wash one's hands before preparing food [2]. 
A wide variety of etiological agents are responsible for causing food borne diseases, the most prominent emerging problems are of microbial origin responsible for $79 \%$ of the FBD burden. The most significant pathogens are Salmonella spp., toxigenic Escherichia coli, Norovirus and Campylobacter [1, 2].

The high burden of infectious diseases and inappropriate use of antibiotics to humans, animals, and agriculture contribute for the emergence of antimicrobial resistance globally, particularly in developing countries [3]. The previous studies have shown an increasing incidence of multidrug resistance in food borne enteric pathogens, particularly to the commonly used antimicrobial agents such as ampicillin, chloramphenicol, streptomycin, sulphadiazine and tetracycline $[3,4]$.

Most of the studies conducted in Ethiopia were institution based, for instance a hospital-based Summary report by the Ministry of Health revealed that the annual incidence of food-borne illnesses ranged from 3.4 to $9.3 \%$, the median is 5.8\% [5]. Furthermore, studies conducted in different parts of the country documented that Salmonella spp, Shigella spp, Escherichia coli, and Staphylococcus aureus were the most common isolates from food handlers with a high rate of drug resistance to the commonly used antibiotics [6-8]. However, there are limited data in Gondar town. Therefore, the aim of this study was to determine the prevalence of enteric bacterial pathogens and their antimicrobial susceptibility patterns among food handlers working in Gondar town restaurants and hotels, Northwest Ethiopia.

\section{Methods}

\section{Study design, area and population}

A cross-sectional study was conducted from February to April 2018 among food handlers working at food establishments found in Gondar town. The town is located $747 \mathrm{~km}$ Northwest of Addis Ababa and $182 \mathrm{~km}$ far from BahirDar, the capital city of the Amhara regional state. According to the Federal Democratic Republic of Ethiopia Central Statistical Agency of Population projection values of 2017, the total population of the town is 360,600 (176,593 males and 184,007 females) [9]. It has 13 sub-cities which consist of 25 kebeles and various food establishments such as hotels and restaurants.

\section{Sample size and sampling technique}

The minimum sample size was calculated based on the assumption of $5 \%$ expected margins of error and $95 \%$ confidence interval, taking the prevalence of enteric bacteria (8.7\%) from the previous study which was conducted in WolaitaSodo town [8] using a single population proportion formula. Since the total number of the source population was less than 10,000, correction formula was used to adjust and it gives 95 . Finally, by considering a 10\% non-response rate and design effect of 2 , the final minimum sample size was 210 study participants. The study participants were sampled by using a multistage sampling technique. The primary procedure was selecting the sub-cities followed by selection of the catering establishments. Five sub-cities were selected by simple random sampling methods using lottery methods among the existing 13 administrative subcities of Gondar town. Subsequently, a comprehensive list of existing catering establishment was obtained from the Gondar trade administration office and the entire catering establishment list within those selected sub cities was stratified as hotels and restaurants. A proportion sampling technique was used to determine for each stratum and the selection was performed using simple random sampling by lottery methods.

\section{Data collection}

Socio-demographic data was gathered using a structured pre-tested questionnaire. The questionnaire included information on sex, age, educational status, and service year among others.

\section{Specimen collection, culture and identification}

Stool samples were collected using clean, dry and leakproof stool cups and immediately placed into Cary-Blair transport medium (Oxoid Ltd., Basingstoke, UK). Samples were transported to University of Gondar Medical Microbiology Laboratory in cold box with ice-packs within $2 \mathrm{~h}$ of collection for further processing. Stool samples were directly inoculated onto MacConkey agar, Salmonella-Shigella agar and Xylose Lysine Deoxycholate agar after enrichment with Selenite cystine broth and incubated at $37^{\circ} \mathrm{C}$ for $18-24 \mathrm{~h}$. After incubation, isolates were characterized by following the standard biochemical test, including triple sugar iron, Hydrogen sulfide production, indole production and motility in sulfide-Indole-motility medium, citrate utilization, lysine decarboxylase in simmon's citrate agar, and urease production [10]. The E.coli isolates were also sub-cultured onto Sorbitol MacConkey agar to identify Enterohemorrhagic Escherichia coli (EHEC) and colorless colonies (nonsorbitol fermenter) were serologically confirmed using IGM antibodies to E. coli O157:H7 [8]. All the biochemical media were obtained from Oxoid Ltd., (Basingstoke, UK).

\section{Antimicrobial susceptibility testing}

The antibiotic susceptibility testing of all strains were carried out on Muller-Hinton agar (Oxoid, UK) with antibiotic discs (Oxoid, UK) using Kirby-Bauer disc diffusion technique against amoxicillin $(30 \mu \mathrm{g})$, ampicillin $(10 \mu \mathrm{g})$, chloramphenicol $(30 \mu \mathrm{g})$, ciprofloxacin $(5 \mu \mathrm{g})$, ceftriaxone $(30 \mu \mathrm{g})$, nalidixic acid $(30 \mu \mathrm{g})$, co-trimoxazole (trimethoprim-sulfamethoxazole) $(25 \mu \mathrm{g})$, gentamicin $(10 \mu \mathrm{g})$, and tetracycline $(30 \mu \mathrm{g})$ based on the guidelines adapted from Clinical and Laboratory Standards Institute (CLSI 2017 
edition), the results were reported as sensitive, intermediate and resistance [11]. For statistical analysis, all isolates with intermediate reactions were classified as resistant. Multidrug resistance (MDR) is defined as the resistance of an isolate to three and more antimicrobial agents within one class of drug [7].

\section{Data analysis and interpretation}

Data were entered into Epi-data 3.1 software and then exported to SPSS version 20 for analysis. Descriptive statistics such as median, inter quartile range, standard deviation, frequencies and percentages were computed. To check the association between dependent and independent variables, $5 \%$ level of precision was used.

\section{Results}

\section{Socio-demographic characteristics}

A total of 257 food handlers were included in this study. The majority of food handlers were females, 236 (91. 8\%). The median ages and standard deviation of the study participant was $26 \pm 5.36$ ranged from 17 to 47 years with an inter quartile range of 6 . Eight five $(33.1 \%)$ of them were between 27 and 30 years and $78(30.4 \%)$ were between 23 and 26 years old. Most of the food handlers, 119 (46.3\%) were served for a period of 1 to 5 years, 99 (38.5\%) were completed secondary school and all the study participants were asymptomatic for diarrheal illnesses even though the study was designed to include both symptomatic and asymptomatic food handlers. The total of 163 (63.4\%) studied establishments were restaurants (Table 1).

\section{Prevalence of enteric bacteria}

The overall prevalence of enteric bacteria was 34/257 (13. 2\%, [95\% CI, 8.9-17.5\%]). Shigella species was the leading isolate that accounted for 26/257 (10.1\%), of which, 3/257 (1.2\%) isolates were Shigella dysentery, followed by EHEC O157:H7, 5/257 (1.9\%) and Salmonella species, 3/257 (1.2\%) (Table 1).

\section{Antimicrobial susceptibility pattern}

The antimicrobial susceptibility pattern of enteric bacteria to different antibiotics is presented in Table 2. Shigella spp. isolates were susceptible to ciprofloxacin 26 (100\%), ceftriaxone 25 (96.1\%), chloramphenicol 24 (92.3\%), nalidixic acid 24 (92.3\%), and gentamicin 20 (76.9\%). Escherichia coli O157: H7 isolates were 100\% susceptible to ceftriaxone, chloramphenicol, ciprofloxacin, and gentamicin. Salmonella spp. isolates were 100\% susceptible to ampicillin, ceftriaxone, chloramphenicol, ciprofloxacin and nalidixic acid, while $66.7 \%$ of the

Table 1 Distribution of enteric bacteria isolated from food handlers in Gondar town, Northwest Ethiopia, 2018

\begin{tabular}{|c|c|c|c|c|}
\hline Characteristic & Shigella spp $(n, \%)$ & EHEC* O157:H7 $(n, \%)$ & Salmonella spp $(n, \%)$ & Total $(n, \%)$ \\
\hline \multicolumn{5}{|l|}{ Age in year } \\
\hline$\leq 22$ & $5(1.9)$ & $1(0.4)$ & $1(0.4)$ & $7(2.8)$ \\
\hline $23-26$ & $13(5.1)$ & $0(0)$ & $1(0.4)$ & $14(5.4)$ \\
\hline $27-30$ & $7(2.7)$ & $2(0.7)$ & $1(0.4)$ & 10(3.9) \\
\hline$\geq 31$ & $1(0.4)$ & $2(0.7)$ & $0(0)$ & $3(1.2)$ \\
\hline Sub-total & $26(10.1)$ & $5(1.9)$ & $3(1.2)$ & $34(13.2)$ \\
\hline \multicolumn{5}{|l|}{ Educational status } \\
\hline Illiterate & $6(2.3)$ & $2(0.7)$ & $0(0)$ & $8(3.1)$ \\
\hline Primary school & $9(3.5)$ & $1(0.4)$ & $0(0)$ & 10(3.9) \\
\hline Secondary school & $11(4.3)$ & $1(0.4)$ & $3(1.2)$ & 15(5.8) \\
\hline Diploma \&above & $0(0)$ & $1(0.4)$ & $0(0)$ & $1(0.4)$ \\
\hline Sub-total & $26(10.1)$ & $5(1.9)$ & $3(1.2)$ & 34(13.2) \\
\hline \multicolumn{5}{|l|}{ Service year (in years) } \\
\hline$<1$ & $12(4.7)$ & $3(1.2)$ & $0(0)$ & $15(5.8)$ \\
\hline $1-5$ & $11(4.3)$ & $1(0.4)$ & $1(0.4)$ & 13(5.1) \\
\hline$>6$ & $3(1.2)$ & $1(0.4)$ & $2(0.7)$ & $6(2.3)$ \\
\hline Sub-total & $26(10.1)$ & $5(1.9)$ & $3(1.2)$ & $34(13.2)$ \\
\hline \multicolumn{5}{|l|}{ Place of work } \\
\hline Hotel & $7(2.7)$ & $1(0.4)$ & $0(0)$ & $8(3.1)$ \\
\hline Restaurant & $19(7.4)$ & $4(1.5)$ & $3(1.2)$ & $26(10.2)$ \\
\hline Sub-total & 26(10.1) & $5(1.9)$ & $3(1.2)$ & $34(13.2)$ \\
\hline
\end{tabular}

EHEC*: Enterohemorrhagic Escherichia coli 
Table 2 Antimicrobial susceptibility pattern of enteric bacteria isolated from food handlers at Gondar town, Northwest Ethiopia, 2018

\begin{tabular}{|c|c|c|c|c|c|c|c|c|c|c|}
\hline \multirow[t]{2}{*}{ Bacterial Isolates } & & \multicolumn{9}{|c|}{ Antimicrobial susceptibility pattern $(n, \%)$} \\
\hline & & $\operatorname{AML}(n, \%)$ & $\operatorname{AMP}(n, \%)$ & $\mathrm{CRO}(\mathrm{n}, \%)$ & $\mathrm{CHL}(\mathrm{n}, \%)$ & $\mathrm{CIP}(n, \%)$ & SXT $(n, \%)$ & TTC $(n, \%)$ & NA $(n, \%)$ & GEN $(n, \%)$ \\
\hline \multirow[t]{2}{*}{ Shigella species $(n=26)$} & $\mathrm{S}$ & $17(65.4)$ & $10(38.5)$ & $25(96.1)$ & $24(92.3)$ & $26(100)$ & $16(61.5)$ & $9(34.6)$ & $24(92.3)$ & $20(76.9)$ \\
\hline & $\mathrm{R}$ & $9(34.6)$ & $16(61.5)$ & $1(3.9)$ & $2(7.7)$ & 0 & $10(38.5)$ & $17(65.4)$ & $2(7.7)$ & $6(23.1)$ \\
\hline \multirow[t]{2}{*}{ EHEC* O157:H7(n=5) } & $\mathrm{S}$ & $1(20)$ & $1(20)$ & $5(100)$ & $5(100)$ & $5(100)$ & $2(66.7)$ & $1(20)$ & $2(40)$ & $5(100)$ \\
\hline & $\mathrm{R}$ & $4(80)$. & $4(80)$ & 0 & 0 & 0 & $1(33.3)$ & $4(80)$ & $3(60)$ & 0 \\
\hline \multirow[t]{2}{*}{ Salmonella species $(n=3)$} & $S$ & $2(66.7)$ & $3(100)$ & $3(100)$ & $3(100)$ & $3(100)$ & $2(66.7)$ & $1(33.3)$ & $3(100)$ & $2(66.7)$ \\
\hline & $\mathrm{R}$ & $1(33.3)$ & 0 & 0 & 0 & 0 & $1(33.3)$ & $2(66.7)$ & 0 & $1(33.3)$ \\
\hline
\end{tabular}

Key: AML = Amoxicillin, AMP Ampicillin, $\mathrm{CRO}=$ Ceftriaxone, $\mathrm{CHL}=$ Chloramphenicol, $\mathrm{CIP}=$ Ciprofloxacin, $\mathrm{SXT}=$ trimethoprim-sulphamethoxazole, $\mathrm{TTC}=$ Tetracycline, $\mathrm{NA}=$ Nalidixic acid, GEN = Gentamicin, $\mathrm{S}=$ Sensitive $\mathrm{R}=$ Resistant, EHEC*: Enterohemorrhagic Escherichia coli

isolate were susceptible to gentamicin. Multi-Drug Resistance (MDR) was observed in 10 (38.5\%) Shigella spp., of which, 7 (26.9\%) isolates were resistant to more than five antimicrobials. The overall prevalence rate of MDR in this study was 14 (41.2\%) (Table 3).

\section{Discussion}

Several studies have underlined that food handlers with poor personal hygiene could be potential sources of infection due to pathogenic bacteria [12-24]. The overall prevalence of entero-pathogenic bacteria isolates from stool in this study was (13.2\%). This is consistent with the reported prevalence in a study done in South Ethiopia (10\%) [12], Nigeria (17.2\%) [13] and India (13.3\%) [14]. However, it is higher than the reported prevalence by other studies in Gondar, Ethiopia (3.1\%) [15], Addis Ababa, Ethiopia (3.5\%) [16], Nigeria (6.9\%) [17] and Jordan (7.4\%) [18]. The observed differences in rates of bacterial isolation could be attributed to differences in food handling and santiation practice, study period and geographical varation $[14,15]$. These asymptomatic food handler carriers could have continued working unaware of their status of infection by these food borne pathogens and keep transmitting the diseases to the community.

The isolation rate of Shigella species (10.1\%) in our study was in agreement with the study conducted in India

Table 3 Multidrug resistance patterns of pathogenic enteric bacteria isolated from food handlers at Gondar town, Northwest Ethiopia, 2018

\begin{tabular}{lllll}
\hline Bacterial isolates & \multicolumn{3}{l}{ Degree of resistance } & \\
\cline { 2 - 4 } & $\mathrm{R3} n(\%)$ & $\mathrm{R} 4 \mathrm{n}(\%)$ & $R \geq 5 \mathrm{n}(\%)$ & $\mathrm{MDR}^{* *} \mathrm{n}(\%)$ \\
\hline Shigella species $(\mathrm{n}=26)$ & $3(11.5)$ & 0 & $7(26.9)$ & $10(38.4)$ \\
EHEC* O157: $\mathrm{H7}(\mathrm{n}=5)$ & 0 & $1(20)$ & 2 & $3(60)$ \\
Salmonella species $(\mathrm{n}=3)$ & 0 & $1(33.3)$ & 0 & $1(33.3)$ \\
Total (34) & $3(8.8)$ & $2(5.9)$ & $9(26.5)$ & $14(41.2)$ \\
\hline
\end{tabular}

EHEC*: Enterohemorrhagic Escherichia coli, ${ }^{* *} M D R=$ Isolates resistant to 3 or more antibiotics classes. $R 3=$ Resistant to Three antibiotic classes, $R 4=$ Resistant to four antibiotic classes, $R \geq 5=$ Resistant to greater or equal to 5 antibiotics
(9.3\%) [14]. Conversely, this finding was lower than the results of a study conducted in Nigeria (15.5\%) [19], and higher compared to similar studies conducted in Gondar, Ethiopia (3.1\%) [15], Jimma, Ethiopia (0.9\%) [7], Nigeria (2.2\%) [17], and Iran $(0.9 \%)$ [20]. This may indicate poor hygien, both personal and food handling practices and may lead to outbreaks of bacillary dysentery to the public [14]. In this study, EHEC (1.9\%) was found to be in agreement with the study conducted in Ethiopia and India with the prevalence rate of 1.8 and $1.3 \%$, respectively [7, 14]. However, this finding was higher than the study conducted in Kenya (0.1\%) [21] and lower than the previous studies conducted in Ethiopia, Iran and Finland with a prevalence of $6.03,34.5$, and $9 \%$, respectively $[8,22,23]$. The varying detection rates may be explained by differences in the study population and laboratory methods. The 1.9\% EHEC positive food handlers in our study may serve as potential sources of outbreaks in the community.

In this study, the isolation rate of Salmonella (1.2\%) was in agreement with the study conducted in Gondar, Ethiopia (1.08\%) [15], Bahirdar, Ethiopia (1.4\%) [24], India (1.4\%) [14] and Ghana (2.3\%) [25]. On the other hand, it was found to be lower than similar studies done in Ethiopia like Arba Minch (3.0\%) [12], Jimma (4.1\%) [7], Addis Ababa (3.5\%) [16], and in Nigeria (17.2\%) [13] and India (4.0\%) [14]. The the isolation rate of Salmonella in the present study was higher compared to studies done in Iran, Jordan and Thailand, which report no isolation rate of Salmonella from the stools of food handlers [20, 26, 27]. This maight be due to epidomological diference and seasonal variation.

In this study Shigella spp. isolates were highly susceptible to ciprofloxacin $(100 \%)$, ceftriaxone $(96.1 \%)$, chloramphenicol (92.3\%), nalidixic acid (92.3\%), and gentamicin $(76.9 \%)$ which is comparable with the reports from Eastern Ethiopia [28], and in South Ethiopia [12]. Salmonella spp. isolates showed high level of susceptibility to ampicillin, ceftriaxone, chloramphenicol, ciprofloxacin, nalidixic acid, and gentamicin. This is in line with a study done in South Ethiopia [12]. Escherichia coli O157: H7 showed the maximum (100\%) susceptibility to 
ciprofloxacin, ceftriaxone, chloramphenicol, and gentamicin, which is in agreement with previous report from Ethiopia [8]. In this study, among the tested antibiotics, ciprofloxacin, ceftriaxone, chloramphenicol, and gentamicin were found to be the most effective drugs to inhibit the invitro growth of these isolates. Thus, these drugs could be used for empirical treatment of these pathogens in the area where culture facility is not available. Moreover, antimicrobial resistance patterns are influenced by source of the isolates, classes of antimicrobial agents, pressure exerted by antimicrobial use, and geographic location [29].

In the current study, $14(42.2 \%)$ of the isolates were MDR. This is lower than the study conducted in Eastern Ethiopia, 85.7\% [28]. Of the 26 Shigella isolates, 10 (38.4\%) were MDR. This is lower than the previous studies conducted in South Ethiopia (100\%) [12] and Addis Ababa (100\%) [16].This variation may be due to the difference in definition of MDR between the two studies. In the previous studies MDR define as resistance to two or more classes of antimicrobials.

\section{Limitations of the study}

In this study, Campylobacter and many other pathotypes of diarrhoegenic Escherichia coli were not investigated. Moreover, the resistance mechanisms of isolated organisms were not characterized due to limited funding of the study.

\section{Conclusions}

Our study showed high prevalence of enteric bacterial pathogens among food handlers. All isolates were susceptible to ciprofloxacin. However, a substential number of isolates were resistant to commonly prescribed antibiotics and the prevalence of MDR was high. The high number of MDR enteric bacterial pathogens could worsen the management of food handlers and increase the transmission of these difficult to treat enteric bacterial pathogens in the community. Therefore, a reliable surveillance system needs to be established to determine the presence of enteric bacterial pathogens among food handlers. Ciprofloxacin, ceftriaxone, chloramphenicol, and gentamicin could be used as therapeutic option in the area where culture facility is not available. Regular medical check up and health education on good hygien practice for food handlers could minimize the prevalance of enteric bacterial pathogens anong food handlers and thereby limit the risk of transmission of entreic bacterial pathogens to the community.

\section{Abbreviations \\ EHEC: Enterohaemorrhagic Escherichia coli; FBD: Foodborne Disease; MDR: Multidrug Resistance}

\section{Acknowledgments}

We would like to thank the study participants for their willingness to participate in the study, hotel and restaurant managers for their support and permission to conduct this study at their food establishments.

\section{Author's contribution}

MG conceived the study, designed data collection, performed the sample collection and laboratory investigations, conducted data analysis and interpretation. WA and BT conceived the study, designed data collection, interpreted the results and reviewed the initial and final drafts of the manuscript. All authors read and approved the final version of this manuscript.

\section{Funding}

No specific grant.

\section{Availability of data and materials}

All data generated or analyzed during this study were included in this article.

\section{Ethics approval and consent to participate}

This research was conducted after obtaining Ethical clearance from the University of Gondar, School of Biomedical and Laboratory Sciences, ethical review committee and support letters were obtained from North Gondar hotel and tourism management bureau prior to data collection. Permissions were obtained from the concerned bodies of the Zonal Health office. The formal letter was also obtained from the Municipality of the town and written informed consent was obtained from each study participant.

Consent for publication

Not applicable.

\section{Competing interests}

The authors declare that they have no competing interests.

\section{Author details}

'Department of Laboratory, University of Gondar Comprehensive Specialized Hospital, Gondar, Ethiopia. ${ }^{2}$ Department of Medical Microbiology, School of Biomedical and Laboratory Sciences, College of Medicine and Health Sciences, University of Gondar, P.O.Box:196, Gondar, Ethiopia.

Received: 11 January 2019 Accepted: 3 July 2019

Published online: 08 July 2019

\section{References}

1. World Health Organization. WHO estimates of the global burden of foodborne diseases: foodborne disease burden epidemiology reference group 2007-2015.

2. Kirk MD, Pires SM, Black RE, Caipo M, Crump JA, Devleesschauwer B, Döpfer D, Fazil A, Fischer-Walker CL, Hald T, Hall AJ. World health organization estimates of the global and regional disease burden of 22 foodborne bacterial, protozoal, and viral diseases, 2010: a data synthesis. PLoS Med. 2015 Dec 3;12(12):e1001921.

3. Okeke IN, Laxminarayan R, Bhutta ZA, Duse AG, Jenkins P, O'Brien TF, Pablos-Mendez A, Klugman KP. Antimicrobial resistance in developing countries. Part I: recent trends and current status. Lancet Infect Dis. 2005 Aug 1;5(8):481-93.

4. Woodward DL, Rodgers FG. Surveillance of antimicrobial resistance in Salmonella, Shigella, and Virvio cholerae in Latin America and the Caribbean: a collaborative project. Canadian Journal of Infectious Diseases and Medical Microbiology. 2000;11(4):181-5.

5. Kalekidan T, Behailu K, Habahwi R. The Ethiopian perception on food safety system. Advances in Food Science and Technology. 2014;2(9):260-8.

6. Dagnew M, Tiruneh M, Moges F, Gizachew M. Bacterial profile and antimicrobial susceptibility pattern among food handlers at Gondar University cafeteria, Northwest Ethiopia. Journal of Infectious Diseases and Therapy. 2013 Apr;30:1-6.

7. Worku T, Jejaw A, Kannan S, Wondafrash B. Isolation and antimicrobial susceptibility patterns of enteric bacterial pathogens from asymptomatic food handlers, Jimma, Ethiopia. American Journal of Health Research. 2015; 3(6):399-406

8. Wadillo F, Molla T, Azene H, Naba T, Shigella Serogroups. Entro-Hemoragic E. coli and Their Antibiogram Pattern Among Food Handlers in FoodHandling Establishments in Southern Ethiopia. American Journal of Life Sciences. 2017:5(2):46-51.

9. Federal Democratic Republic of Ethiopia Central Statistical Agency Population Projection of Ethiopia for All Regions at Wereda Level from; 2014-2017. 
10. Cheesbrough M. District laboratory practice in tropical countries. New York, NY, USA: Cambridge University Press; 2006.

11. CLSI, editor. Performance Standards for Antimicrobial Susceptibility Testing. $27^{\text {th }}$ ed. CLSI supplements M100. Clinical and Laboratory Standards Institute: Wayne, PA; 2017.

12. Mama M, Alemu G. Prevalence, antimicrobial susceptibility patterns and associated risk factors of Shigella and Salmonella among food handlers in Arba Minch University, South Ethiopia. BMC Infect Dis. 2016 Dec;16(1):686.

13. Smith $\mathrm{SI}$, Alao F, Goodluck HT, Fowora M, Bamidele M, Omonigbehin E, Coker AO. Prevalence of Salmonella typhi among food handlers from bukkas in Nigeria. Br J Biomed Sci. 2008 Jan 1;65(3):158-60.

14. Khurana S, Taneja N, Thapar R, Sharma M, Malla N. Intestinal bacterial and parasitic infections among food handlers in a tertiary care hospital of North India. Trop Gastroenterol. 2010 Mar 21;29(4):207-9.

15. Andargie G, Kassu A, Moges F, Tiruneh M, Huruy K. Prevalence of bacteria and intestinal parasites among food-handlers in Gondar town, northwest Ethiopia. Journal of health, population, and nutrition. 2008 Dec;26(4):451.

16. Aklilu A, Kahase D, Dessalegn M, Tarekegn N, Gebremichael S, Zenebe S, Desta K, Mulugeta G, Mamuye Y, Mama M. Prevalence of intestinal parasites, salmonella and shigella among apparently health food handlers of Addis Ababa University student's cafeteria, Addis Ababa, Ethiopia. BMC research notes. 2015 Dec;8(1):17.

17. Umo A. Okon. Asymptomatic carriers of enteric pathogens andthe risk factors among food handlers in a rural setting in Nigeria. Journal of Advances in Microbiology. 2017;4(3):1-6.

18. Al-Lahham AB, Abu-Saud M, Shehabi AA. Prevalence of Salmonella, Shigella and intestinal parasites in food handlers in Irbid, Jordan. J Diarrhoeal Dis Res. 1990 Dec;1:160-2.

19. Ifeadike CO, Ironkwe OC, Adogu PO, Nnebue CC, Emelumadu OF, Nwabueze SA, Ubajaka CF. Prevalence and pattern of bacteria and intestinal parasites among food handlers in the Federal Capital Territory of Nigeria. Nigerian medical journal: journal of the Nigeria Medical Association. 2012 Jul;53(3):166

20. Nasrolahei M, Mirshafiee S, Kholdi S, Salehian M, Nasrolahei M. Bacterial assessment of food handlers in Sari City, Mazandaran Province, north of Iran. Journal of infection and public health. 2017 Mar 1;10(2):171-6.

21. Oundo JO, lijima Y, Boga HI, Muli F, Kariuki S. Molecular typing and antibiotic sysceptibility patterns of enteropathogenic and shigatoxin producing Escherichia coli isolated from food handlers in three areas of Kenya. East Afr Med J. 2009;86(6):279-86.

22. Jafari F, Hamidian M, Rezadehbashi M, Doyle M, Salmanzadeh-ahrabi S, Derakhshan F, Reza ZM. Prevalence and antimicrobial resistance of diarrheagenic Escherichia coli and Shigella species associated with acute diarrhea in Tehran, Iran. Canadian journal of infectious diseases and medical microbiology. 2009;20(3):e56-62.

23. Lääveri T, Antikainen J, Pakkanen SH, Kirveskari J, Kantele A. Prospective study of pathogens in asymptomatic travellers and those with diarrhoea: aetiological agents revisited. Clin Microbiol Infect. 2016 Jun 1;22(6):535-41.

24. Abera B, Biadegelgen F, Bezabih B. Prevalence of Salmonella typhi and intestinal parasites among food handlers in Bahir Dar Town, Northwest Ethiopia. Ethiopian. Journal of Health Development. 2010;24(1):46-50.

25. Feglo PK, Frimpong EH, Essel-Ahun M. Salmonellae carrier status of food vendors in Kumasi, Ghana. East Afr Med J. 2004:81(7):358-61.

26. Abdel-Dayem M, Al Zou'bi R, Hani RB, Amr ZS. Microbiological and parasitological investigation among food handlers in hotels in the Dead Sea area, Jordan. J Microbiol Immunol Infect. 2014 Oct 1;47(5):377-80.

27. Kusolsuk T, Maipanich W, Nuamtanong S, Pubampen S, Sa-nguankiat S, Rojekittikhun W, Lekkla A, Tunyong W, Chettanadee S, Komalamisra C. Parasitic and enteric bacterial infections among food handlers in tourist-area restaurants and educational-institution cafeterias, Sai-yok district, Kanchanaburi province. Thailand.

28. Marami D, Hailu K, Tolera M. Prevalence and antimicrobial susceptibility pattern of Salmonella and Shigella species among asymptomatic food handlers working in Haramaya University cafeterias, eastern Ethiopia. BMC research notes. 2018 Dec;11(1):74.

29. Pickering LK. Antimicrobial resistance among enteric pathogens. InSeminars in pediatric infectious diseases 2004 Apr 1 (Vol. 15, no. 2, pp. 71-77). WB Saunders.

\section{Publisher's Note}

Springer Nature remains neutral with regard to jurisdictional claims in published maps and institutional affiliations.

Ready to submit your research? Choose BMC and benefit from:

- fast, convenient online submission

- thorough peer review by experienced researchers in your field

- rapid publication on acceptance

- support for research data, including large and complex data types

- gold Open Access which fosters wider collaboration and increased citations

- maximum visibility for your research: over $100 \mathrm{M}$ website views per year

At BMC, research is always in progress.

Learn more biomedcentral.com/submissions 